\title{
EDITORIAL
}

\section{The COVID-19 Pandemic and its impact on wildlife}

\author{
D.K Sharma ${ }^{1, *}$ and Chittaranjan Baruah ${ }^{2}$ \\ ${ }^{1}$ Department of Zoology, University of Science \& Technology, Meghalaya - 793101, India \\ ${ }^{2}$ Postgraduate Department of Zoology, Darrang College (Affiliated to Gauhati University), Tezpur- 784001, India
}

COVID-19 is possibly the greatest and most enormously significant crisis against humans in the planet's modern history. The group of Coronaviridae includes viruses with very long RNA genomes of up to 33,500 nucleotides. SARS-CoV-2 belongs to the Sarbecovirus family, with an approximate genome size of 30.000 nucleotides (Wu et al., 2020). SARS-CoV-2 has four main structural proteins: spike (S), envelope (E), membrane (M), and nucleocapsid $(\mathrm{N})$. Additionally, some other non-structural proteins are encoded in the ppla and pplab polyproteins, essential for viral replication (Wu et al., 2020; Baruah et al., 2020; Baruah et al., 2021; Sharma and Baruah, 2021). The coronavirus has upended our way of life, but it's also having a dramatic impact on animals across the globe too, from black rhinos being poached in Botswana to a coughing tiger in New York and emboldened goats on the streets of Wales.

Current view, based on certain evidence, says the coronavirus originated in bats, yet it is not known how it got into the human populace, causing pandemic situations in 2020 and 2021 as the first and second waves of infectivity, with the death of several hundred thousand human lives. Researchers overwhelmingly believe that it's a wild virus, which was probably passed to people through an intermediate species. But no one has found the virus in the wild yet, so other explanations cannot be ruled out entirely.

Given the similarity of SARS-CoV-2 to bat SARS-CoV-like coronaviruses2, it is likely that bats serve as reservoir hosts for its progenitor. Although the genome named RaTG13, sampled from a bat named Rhinolophus affinis (Wan et al., 2020), is $96 \%$ identical to SARS-CoV-2, its spike diverges in the receptor binding domain (RBD), which suggests that it may not bind efficiently to human ACE2 (Zhou et al., 2020). That RATG13 was $96 \%$ identical to SARS-CoV-2, making it the closest known relative and strongly suggesting the new virus originated in bats.

Pangolins were among the first animals suspected of being the intermediates. Two teams in China reported that they'd found similarities between SARS-CoV-2 and coronaviruses isolated from tissue of Malayan pangolins (Manis javanica) that had been confiscated. Trading pangolins is illegal in China. Malayan pangolins (Manis javanica) illegally imported into Guangdong province contain coronaviruses similar to SARS-CoV-2 (Zang et al., 2020). Although the RaTG13 bat virus remains the closest to SARS-CoV-2 across the genome (Zhou et al., 2020), some pangolin coronaviruses exhibit strong similarity to SARS-CoV-2 in the RBD, including all six key RBD residues (Zang et al., 2020). This clearly shows that human-like ACE2 is the result of natural selection. However, pangolin coronaviruses turned out to be too distant to be direct ancestors of SARS-CoV-2. However, they are the only wild mammals besides bats living with coronaviruses similar to SARS-CoV-2, suggesting an intermediate source.

It has been well argued that many species, like cats, fruit bats (Rousettus aegyptiacus), ferrets, rhesus macaques, and hamsters, have been shown to be susceptible to SARS-CoV-2. Outside the laboratory, animals including pet cats and dogs, tigers and lions at zoos, and farmed mink have also caught the virus - probably from people. So far, more than 215 vertebrates have found that the receptor in many mammals, including sheep, chimpanzees, and gorillas, engages well with the spike protein on the surface of the virus, which suggests that these animals might be susceptible to infection.

The negative perception of wildlife as disease carriers may result in retaliatory killings of possible carrier species such as bats and pangolins, resulting in severe repercussions for these threatened species (Kissui, 2008). For example, all Asian pangolins are endangered or critically endangered, and any future retaliatory killings may push the species toward extinction. Human migration and a jobless atmosphere might put added pressure on wildlife and habitats for food and livelihood by way of increased poaching, hunting, and logging, leading to closer contact between humans and wildlife and possibly causing certain zoonotic diseases (Bloomfield et al., 2020). Reducing the likelihood of another viral spillover sweeping the world requires a fundamental change in how we interact with nature. It requires minimizing human interface with wild animals and wild spaces and eliminating transmission points where the likelihood of viral spillover to humans is high, such as unhygienic commercial markets in wild animal meat and live animals. Effective monitoring of the legal trade in wildlife has diligently suppressed the illegal and unsustainable trade in wildlife and conserved natural habitats. Conserving natural habitats in turn requires profound changes in human food production and human encroachment on remaining natural habitats, but such changes are necessary despite having lots of difficulties (Felbab-Brown, 2021). While such instances have been witnessed in other parts of the globe, lions testing positive in Hyderabad's zoo - spread over 300 acres and home to over 1500 species of animals and birds - is one of the first such cases in India. After veterinarians in the zoo began noticing the eight lions around the 40 -acre safari area displaying symptoms of the virus, officials

*Corresponding Author's E-mail: dksgu@yahoo.co.uk 
from the Nehru Zoological Park tested eight Asiatic lions for the virus. Of the eight lions, four were males, and the other four were females. The results were publicly announced after the Centre for Cellular and Molecular Biology, Hyderabad, informed authorities at the zoo.

In early 2020, a Pomeranian in Hong Kong tested "weakly positive" for the virus but did not exhibit any symptoms. The Society for the Protection of Animals in Hong Kong specified that being infected was not the same as being infectious and capable of spreading the virus. In April 2020, lions and tigers at the Bronx Zoo in New York City tested positive for the virus. All of the animals at the Bronx Zoo made full recoveries. Again in September, four lions tested positive at a zoo in Barcelona. Like their counterparts across the globe, they responded well to treatment. The wave of negativity has also recently been observed in Assam, India. Nearly 200 egret and cormorant hatchlings died (killed) on June $8^{\text {th }}, 2021$ after bamboo trees were felled in the Udalguri district over the fear of the spread of COVID-19 from the bird droppings, resulting in the destruction of the egret nests and many eggs and hatchlings falling on the ground.

There has been a reported increase in the poaching and illegal treading of live animals of certain species in India ever since the COVID-19 pandemic hit India. Experts call for a unified strategy to confront poaching and protect overall biodiversity in India. Traffic, a programme division of WWF, deals with the trade of wildlife and the conservation of biodiversity. According to a June 2020 report, during the six-week lockdown, known poaching cases increased from 35 to 88 instances, compared to the six weeks before the lockdown. The most affected groups were ungulates (22 pc to $44 \mathrm{pc}$ ) and smaller mammals such as pangolins and monkeys (17 pc to $25 \mathrm{pc}$ ). Poaching, therefore, is only one of the worrying aspects of animal endangerment. Lockdowns disrupted conservation enforcement and research efforts, and in many places, illegal hunting and fishing increased as poor, desperate people looked for ways to compensate for lost income or food. The ecotourism activities that provide financial support for many conservation efforts dried up, and many restoration projects had to be cancelled or postponed. Parks that were open to visitors were inundated by abnormally large crowds. They have been facing an abnormally calm and quiet situation. And in many places, hikers expanded trails, destroyed habitats, and even trampled endangered plants (Owens, 2021).

Hunting for bush meat has significantly increased in most forest fringe areas. People are sitting at home, in places where wildlife is easily available, roaming around and free of cost. Some of the incidents include a group of endangered Indian gazelles being poached and some other wild animals, including barking deer (Muntiacus muntjak) that were shockingly killed as a declaration of a "lockdown festival" by a group of hunters. The trade in live animals is often much more organized and widespread, not only in India but across the world. In the past, there was also a lot of trading, but in the last two to three years, all sorts of animals began coming to India because of changes in the economy and tastes that people developed. This international trade import includes turtles, tortoises, snakes, iguanas, and other reptiles. There is a well-established market in India, where the northern and Bangladesh borders are largely used as transit routes. Kolkata is also one of the hubs into which the animals are brought.

Ironically, considering the wildlife trade in China is suspected to be the root of the coronavirus infection, this is especially disquieting. Despite trade routes being blocked due to pandemic restrictions, traders are finding new ways to overcome legal barriers.

A steady increase in online trade, where people use online platforms to undertake illegal activities, there is an increase in attempts by suspects to use social media for such activities. This trend is alarming and will be difficult to deal with. Moreover, across India, there has been a trend of courts granting bail to suspects due to COVID-19, even in such cases. Even pangolins, which are especially popular for their meat and scales, are being collected and kept in covert "hotspots" by traders who wish to continue the business as they did before the COVID-19 lockdown. Interestingly, the response of wildlife to changes in the functioning of human society and the economy was also rapid. The first phenomenon noticed was that the reduction in human disturbance allowed wildlife to exploit built-up habitats and to increase daily activity (Manenti et al., 2020).

Since the beginning of the pandemic, evidence of the presence of wild animal species in areas where they have not been seen for a long time has been shared on social media (Derryberry et al., 2020, Abd Rabou 2020, Bar 2020). A number of various changes in animal behaviour have also been noticed, such as in birds' vocalisations during the COVID-19 quietus (Derryberry et al., 2020), increased aggression, changes in feeding sites, and the formation of new competitive systems in synanthropic species suddenly deprived of anthropogenic food (Rutz et al., 2020, Gilby et al., 2021). During the pandemic, people have been given the opportunity to gain unanticipated insight into how their presence affects animal behaviour and how quickly and flexibly animals can react to unprecedented changes, such as lockdown and the "global human confinement experiment" (Bates et al., 2020; Montgomery et al., 2021). It has often been asked about the stable effect of the COVID-19 pandemic on wildlife and whether the anthropogenic lockdown may reverse the negative trends in the decline in the number of wild species (Lopucki et al., 2021).

Zoo animals are now considered to be getting sick, possibly due to missing human attention. The coronavirus is a zoonotic disease, meaning it has jumped from animals to humans. Now, it seems to be jumping back. A tiger at the Bronx Zoo tested positive for the coronavirus. It is thought the tiger, named Nadia, along with six other big cats, was infected by an asymptomatic zoo keeper. The cats have been showing symptoms, including a dry cough. Zoos across the globe have been closed as part of a national lockdown, and zookeepers say their most intelligent and social animals - including gorillas, otters, and meerkats - are missing the attention of humans.

Wildlife is running wild with human selfisolation in their homes. Animals that usually stay away from urban areas now have space to roam. A herd of deer was caught on camera walking the streets of Haridwar, India during the nationwide COVID-19 lockdown. Also, there has been a massive spike in the number of baby Olive Ridley sea turtles as beaches lie empty of humans. It's thought that around 60 million eggs have been deposited on Indian beaches this year.

One of the immediate responses to COVID19 has been a call to ban wildlife trade given the suspected origin of the pandemic in a Chinese market selling and butchering wild animals. There is clearly 
an urgent need to tackle wildlife trade that is illegal, unsustainable or carries major risks to human health and biodiversity conservation. However, the calls for bans on wildlife markets often include calls for bans on wet markets, but the two are not the same thing, and wet markets could be a critical underpinning of informal food systems. Second, the wildlife trade generates essential resources for the world's most vulnerable people, contributing to food security for millions of people, particularly in developing countries. Even a ban on wildlife trade has conservation risks, including driving trade underground, making it even harder to regulate, and encouraging further livestock production. Moreover, in many cases, sustainable wildlife trade can provide key incentives for local people to actively protect species and the habitat they depend on, leading to population recoveries. Most importantly, a singular focus on wildlife trade overlooks the key drivers of the emergence of infectious diseases: habitat destruction, mostly driven by agricultural expansion and deforestation, and industrial livestock production. Thus, the COVID-19 crisis provides a unique opportunity for a paradigm shift both in our global food system and also in our approach to conservation (Roe et al., 2020). Zoonosis-based epidemics are inevitable unless we revisit our relationship with the natural world, protect habitats, and regulate wildlife trade, including live animals and non-sustenance products. To prevent future zoonoses, governments must establish effective legislation addressing wildlife trade, habitat protection, and reduction of the wildlife-livestock-human interface (Borzee et al., 2020).

Environmental degradation is increasing the likelihood of future pandemics like COVID-19, as habitat loss and poaching increase close contact between wildlife and people. This fact has been framed as a reason to increase wildlife conservation efforts. We have many good reasons to step up conservation efforts, but arguments for doing so on the basis of pandemic prevention are rhetorically, ethically, and empirically flawed (Santana 2020). Even in India's lockdown, human-wildlife conflicts persisted, increasing in towns that became unusually quiet. Asian elephants were more regularly exploring human spaces in the states of Assam, West Bengal, and Kerala in search of food and, in the case of solitary tusker elephants, to expand their territories, potentially resulting in potentially fatal consequences.

The effects of the COVID-19 pandemic lockdown period have been reflected on the behaviour of aquatic life. COVID-19 lockdown extends to the optimal aquatic environment and aquatic life (CNN News Reporting, June, 2020). When sea beaches are closed due to lockdowns, turtles are often found nesting in peace in Florida (CNN 2020).A South Asian river dolphin known as the "Gangetic Dolphin" was back in Kolkata, India, nearly three decades after (Times of India, 2020). All the evidence is somehow related to the instant change in the ecosystem of the forest and water.

There is a huge negative impact of noise pollution on birds' lives. So the silence lockdown appears to have a peaceful living effect on the birds. Typical changes in the behaviour of partial migratory birds are observed, and they stay in sanctuaries a bit longer. Bird species like open-billed stork, painted stork, grey heron, spoonbill, spot-billed pelican, and ibis generally leave here by March in India. But they have extended their stay period, which may be due to less human activity and less noise pollution in the lockdown period (The Hindu 2020). Birds and butterflies have surged significantly across the country. Resident birds are breeding much more than before due to less human activity, no noise and air pollution (India New England ,2020).

Pets also have some routine activities. In the lockdown period, the restriction affects their normal behaviour pattern. Sometimes they become ferocious and behave in an abnormal way. Though common pets like dogs, chickens, pigs, and ducks are not likely to be infected, pet owners have no scope to move them. Cats are suspected to carry and spread the virus, and special care is needed for such species (Nature News 2020).

Generally, local street dogs, cats, monkeys, crows, and free birds depend on the food of tourists and domestic people. During lockdown, they are in a food crisis, sometimes fighting with each other in the process. Afterward, the government and a few NGOs are arranging "natural restaurants" for the animals. The roaming of wild animals in residential areas may be due to a shortage of food. To cite an example, the deer in Nara Park, Japan are usually fed by visitors, but during the lockdown period, food is dried up as a result of which they might have left the park and taken to the streets of the city to look for food.

The worldwide animal market, where thousands of species are bought and sold every year, is a serious threat to biodiversity. As the COVID-19 outbreak has started in the Hunan seafood market, China has temporarily banned wildlife trading (Chakrabarty and Maity, 2020). As it is supposed that transferable diseases originate from animals, different countries permanently ban wildlife tread, which is regarded as good criteria for wildlife health and restoring the sustainable eco-system. Saadat et al. (2020) conducted a survey in Hong Kong and discovered a large number of masks, as well as other disposals, along a high-tied line of the seashore. If biomedical waste is not discarded according to medical protocol, it can infect and even kill animals and aquatic life by mistakenly eating it (Hellewell et al. 2020), and the ecosystems of both land and water can suffer as a result. Therefore, the restructuring of policies regarding medical waste management under COVID-19 has been the need of the hour. Handling of COVID-19 dead bodies is another new environmental issue. The number of deaths in COVID-19 till date is around 4.5 million (as on September 6, 2021) and is supposed to be increased by every hour. Dead bodies need to be mass buried rather than handed over to their families for ritual.

Pangolins are the world's most trafficked mammals. Just like rhinos and many other wildlife species, pangolins are falsely believed to possess medicinal and spiritual properties. In some Asian cultures, the scales of pangolin are believed to cure hangovers, impotence, and even cancer. Pangolin meat is considered a rare delicacy in several countries, a "luxury" reserved only for the most elite. Somewhat ironically, pangolins are also suffering in Africa due to the bush meat trade. In some countries, the locals are willing to eat any animal they come across to sustain themselves and their families.

Despite numerous media reports and an increasing number of scientific papers documenting the impact of the global lockdown on unusual animal behavior, information on changes in fertility, mortality, or genetic effects remains lacking (Derryberry et al., 2020, Rutz et al., 2020; Abd Rabou, 2020; Bar, 2020; 
Montgomery et al., 2021). There has been tremendous difficulty in recording all these features and effects on such a small group of people within such a minimal span of time. However, in the case of the analyzed species, this effect could be reliably shown, as traffic-related mortality of hedgehogs is well-known and widely described; hedgehogs die on roads throughout the entire year, except during winter hibernation, and the peak mortality is during the summer months (Kristiansson, 1990; Rondinini, and Doncaster, 2002; Haig et al., 2014; Rautio et al., 2016; Wright, et al., 2020). One reason is hedgehogs' promiscuous mating systems (Haig et al., 2014). But the pandemic has had a great impact on the killings of such animals on the road. The pandemic has also shown us that seemingly extreme solutions and their implementation, such as a mandatory lockdown.

To conclude, it is essential to understand how an animal virus jumped species boundaries to infect humans so productively, helping in the prevention of future zoonotic events. If SARS-CoV-2 is pre-adapted in another animal species, then there is a risk of future re-emergence events. In contrast, if the adaptive process occurred in humans, then even if repeated zoonotic transfers occur, they are unlikely to take off without the same series of mutations (Wu et al., 2020). In addition, identifying the closest viral relatives of SARS-CoV-2 circulating in animals will greatly assist studies of viral function (Zang et al.,2020).SARS-CoV-2's infectiousness and transmissibility in humans may be explained in part by genomic features. However, it is observed that all notable SARS-CoV2 features, including the optimized RBD and polybasic cleavage site, are related to coronaviruses in nature (Zhou et al., 2020). More scientific data could swing the balance of evidence to favour one hypothesis over another. Obtaining related viral sequences from animal sources would be the most definitive way of revealing viral origins (Anderson et al., 2020). For example, a future observation of an intermediate or fully formed polybasic cleavage site in a SARS-CoV-2-like virus from animals would lend even further support to the natural-selection hypotheses. It would also be helpful to obtain more genetic and functional data about SARS-CoV-2, including animal studies. The identification of a potential intermediate host of SARS-CoV-2, as well as sequencing of the virus from very early cases, would similarly be highly informative (Andersen et al., 2020). And human activities for a specific duration every year may restore the planetary environment, even if temporarily. If nothing else, such temporary solutions will delay the tipping points of future environmental crises. The scientific community will need to lead from the front in creating solutions and in steering the sociopolitical will required to implement these solutions for a more long-lasting process of environmental conservation. In the absence of such recognition, environmental and biodiversity conservation may take a back seat on national and international agendas following COVID-19 (Zhao et al., 2020).

\section{REFERENCES}

Abd Rabou A.N. 2020. How Is the COVID-19 Outbreak Affecting Wildlife around the World? Open J. Ecol.10, 497-517.

Andersen, K. G., Rambaut, A., Lipkin, W. I., Holmes, E. C., \& Garry, R. F. 2020. The proximal origin of SARS-CoV-2. Nature medicine, 26(4), 450-452. https://doi.org/10.1038/s41591-020-0820-9
Bang, A., \& Khadakkar, S. 2020. Opinion: Biodiversity conservation during a global crisis: Consequences and the way forward. Proceedings of the National Academy of Sciences of the United States of America, 117(48), 29995-29999. https://doi.org/10.1073/pnas.2021460117

Bao, R. and Zhang, A. 2020. Does lockdown reduce air pollution? Evidence from 44 cities in northern China. Sci. Total Environ.731, 139052

Bar, H. 2021. COVID-19 lockdown: animal life, ecosystem and atmospheric environment. Environ Dev Sustain 23, 8161-8178. https:// doi.org/10.1007/s10668-020-01002-7

Baruah C, Devi P, Sharma D.K. 2020. Sequence Analysis and Structure Prediction of SARS-CoV-2 Accessory Proteins 9b and ORF14: Evolutionary Analysis Indicates Close Relatedness to Bat Coronavirus. Biomed Res Int 7234961.

Baruah C, Mahanta S, Devi P, Sharma DK. 2021. In Silico Proteome Analysis of Severe Acute Respiratory Syndrome Coronavirus 2 (SARS-CoV2). J Nanotechnol Nanomaterials. 2(1): 1-19.

Bloomfield LSP, McIntosh TL, Lambin EF.2020. Habitat fragmentation, livelihood behaviors, and contact between people and nonhuman primates in Africa. Landsc. Ecol. 35, 985-1000

Borzée A, McNeely J, Magellan K, Miller JRB et al. 2020. COVID-19 Highlights the Need for More Effective Wildlife Trade Legislation. Trends EcolEvol. 35(12): 1052-1055. doi: 10.1016/ j.tree.2020.10.001.PMID: 33097287

Chakraborty I, Maity P. COVID-19. 2020. Outbreak: Migration, effects on society, global environment and prevention. Sci Total Environ. 2020 Aug 1;728:138882. doi: 10.1016/ j.scitotenv.2020.138882. Epub 2020 Apr 22. PMID: 32335410; PMCID: PMC7175860.

Derryberry E, P Phillips JN, Derryberry GE, Blum MJ, Luther D. 2020. Singing in a silent spring: Birds respond to a half-century soundscape reversion during the COVID-19 shutdown. Science $370,575-579$.

Gilby BL, Henderson CJ, Olds AD, Ballantyne JA Bingham EL. 2021. Potentially negative ecological consequences of animal redistribution on beaches during COVID-19 lockdown. Biol. Conserv. 253, 108926.

Haigh A, O'Riordan RM, Butler F. 2014. Hedgehog Erinaceus europaeus mortality on Irish roads. Wildl. Biol. 20: 155-160.

Hellewell J, Abbott S, Gimma A, Bosse NI, Jarvis CI, Russell TW, Munday JD, Kucharski AJ, Edmunds WJ. 2020. Centre for the Mathematical Modelling of Infectious Diseases COVID-19 Working Group, Funk S, Eggo RM. Feasibility of controlling COVID-19 outbreaks by isolation of cases and contacts. Lancet Glob Health. 8 (4):e488-e496. doi: 10.1016/S2214-109X(20) 30074-7. Epub 2020 Feb 28. Erratum in: Lancet Glob Health. 2020 Mar 5;: PMID: 32119825; PMCID: PMC7097845.

Kissui BM. 2008. Livestock predation by lions, leopards, spotted hyenas, and their vulnerability to retaliatory killing in the Maasai steppe, Tanzania. Anim. Conserv. 11, 422-432. 
Kristiansson H. 1990. Population variables and causes of mortality in a hedgehog (Erinaceus europaeus) population in southern Sweden. Masters Journal of Zoology, London 220: 391-404.

Łopucki R, Kitowski I, Perlińska-Teresiak M, Klic D. 2021. How Is Wildlife Affected by the COVID-19 Pandemic? Lockdown Effect on the Road Mortality of Hedgehogs. Animals 11(3):868.

Manenti R, Mori E, Di Canio V, Mercurio S, Picone M. 2020. The good, the bad and the ugly of COVID-19 lockdown effects on wildlife conservation: Insights from the first European locked down country. Biol. Conserv.249, 108728.

Montgomery RA, Raupp J, Parkhurst M. 2021. Animal Behavioral Responses to the COVID-19 Quietus. Trends Ecol. Evol. 36: 184-186.

Owens B. 2021. smithsonianmag.com May 27, 2021

Rautio A, Isomursu M, Valtonen A, Hirvelä-Koski V, Kunnasranta M. 2016. Mortality, diseases and diet of European hedgehogs (Erinaceus europaeus) in an urban environment in Finland. Mammal. Res. 61: 161-169.

Roe D, Dickman A, Kock R, Milner-Gulland EJ Rihoy E, Sas-Rolfes M. 2020. Beyond banning wildlife trade: COVID-19, conservation and development, World Development, 105121 https://doi.org/10.1016/ j.worlddev.2020.105121

Rondinini A and Doncaster CP. 2002. Roads as barriers to movement for hedgehogs. Funct. Ecol. 16: 504 509. (CrossRef)

Rutz C, Loretto MC, Bates AE, Davidson SC, Duarte CM. 2020. COVID-19 lockdown allows researchers to quantify the effects of human activity on wildlife. Nature Ecol. Evol. 2020, 4: 1156-1159.

Saadat S, Rawtani D, Hussain CM. 2020. Environmental perspective of COVID-19. Sci Total Environ. $1 ; 728: 138870$.
Santana C. 2020. COVID-19, other zoonotic diseases and wildlife conservation.HPLS 42: 45 .https:// doi.org/10.1007/s40656-020-00345-8

Sharma DK and Baruah C. 2021. Bioinformatics and Artificial Intelligence to Combat Covid-19 and Beyond. Bioinformatics and Proteomics Opn Acc J. 5(1): 000140

Wan Y, Shang J, Graham R, Baric RS, Li F. 2020. Receptor Recognition by the Novel Coronavirus from Wuhan: an Analysis Based on DecadeLong Structural Studies of SARS Coronavirus. J Virol. 17;94(7):e00127-20. doi: 10.1128/ JVI.00127-20. PMID: 31996437; PMCID: PMC7081895.

Wembridge DE, Newman MR, Bright PW, Morris PA. 2016. An estimate of the annual number of hedgehog (Erinaceus europaeus) road casualties in Great Britain. Mammal. Commun.2: 8-14

Wright PGR, Coomber FG, Bellamy CC, Perkins SE, Mathews F. 2020. Predicting hedgehog mortality risks on British roads using habitat suitability modelling. Peer J 7 :8154.

Wu F, Zhao S, Yu B, Chen YM, Wang W, et al. 2020. A new coronavirus associated with human respiratory disease in China. Nature 579(7798): 265-269.

Zhang T, Wu Q, Zhang Z. 2020. Probable Pangolin Origin of SARS-CoV-2 Associated with the COVID-19 Outbreak. CurrBiol. 30(7):13461351.e2. doi: 10.1016/j.cub.2020.03.022.

Zhou $\mathrm{P}$, Yang XL, Wang XG, Hu B, Zhang L et al. 2020. Addendum: A pneumonia outbreak associated with a new coronavirus of probable bat origin. Nature. 588(7836): E6. doi: 10.1038/ s41586-020-2951-z.

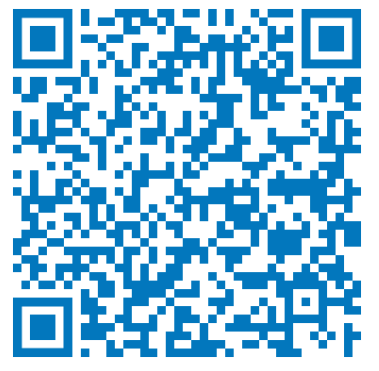

